\title{
Editor's introduction to the exchange between Hofstede and GLOBE
}

\section{Kwok Leung}

Department of Management, City University of Hong Kong, Kowloon, Hong Kong SAR

\section{Correspondence:}

Kwok Leung, Department of Management, City University of Hong Kong, Tat Chee Avenue, Kowloon, Hong Kong SAR.

Tel: + 8522788 9592;

Fax: + 8522788 9085;

E-mail: mkkleung@cityu.edu.hk
Journal of International Business Studies (2006) 37, 88I.

doi: I0.1057/palgrave.jibs.8400232

When I received the critique of the GLOBE project from Hofstede, my immediate reaction was that something earthshaking would emerge from this 'clash of the titans.' Hofstede has originated one of the most influential frameworks in international business research. No less impressive is the scale of the GLOBE project, which is probably the most sophisticated project undertaken in international business research. An open, constructive exchange between the masterminds of these two monumental research programs should be illuminating and trailblazing.

With this objective in mind, I sent Hofstede's paper out for review, and when I was assured of the quality of his critique, I invited the GLOBE team to write a reply. To add to the debate and as an intellectual spark for moving the field forward, I invited two well-known veterans of cultural research, Peter Smith and Chris Earley, not only to provide comments on the debate but also to suggest insights garnered from it for future research. I would like to thank all the authors involved for their patience in working with me to orient the exchange toward setting new research agendas for the field. I am also very grateful to Arie Lewin, whose encouragement and guidance were instrumental to putting together this exchange and setting the right tone for it. I am sure that this set of papers will prove to be a significant milestone for international business research, and serve as a major source of inspiration and innovation for years to come. I invite readers to approach their immersion into the debate with the same goals. 